\title{
Repairing of a timber truss through two different techniques using timber elements and screwed metal plates
}

\author{
Daniele Cibecchini $^{1, a}$, Niclas Bjorngrim ${ }^{2, b}$, Hélder S. Sousa ${ }^{3, c}$ Marco Jorge $^{3, d}$ \\ and Jorge M. Branco ${ }^{3, e}$ \\ ${ }^{1}$ GESAAF - Dept. of Agricultural, Food and Forestry Systems, University of Florence, Italy \\ ${ }^{2}$ Dept. of Wood Science and Technology, Division of Wood Technology, Luleå University \\ of Technology, Skellefteå, Sweden \\ ${ }^{3}$ ISISE - Dept. Civil Engineering, University of Minho, Guimarães, Portugal \\ adaniele.cibecchini@unifi.it, bniclas.bjorngrim@ltu.se, 'sousa.hms@gmail.com, \\ dmarco@civil.uminho.pt, ${ }^{\mathrm{d}}$ jbranco@civil.uminho.pt
}

Keywords: Timber trusses, Repair, Timber elements, Screwed metal plates

\begin{abstract}
Structural reinforcement of timber buildings may be needed due to different reasons such as change of use, deterioration, lack of maintenance, exceptional damaging incidents or loading, to comply with regulatory changes and being retrofitted, or interventions to increase structural resistance.

In this work, two different techniques were considered for repair of a timber truss, subjected only to vertical loads, that was previously assessed on laboratory (test facilities of University of Minho) and taken up to failure during a load-carrying test. A collar beam truss, with more than one hundred years, was tested carrying a vertical point load on each main rafter. Failure of the timber truss was located in the sections of the rafters near the loading positions by bending.

Repairing techniques, based on the use of timber elements for one of the rafters and on screwed metal plates for the other rafter, were evaluated and compared to the original unstrengthened condition.

The efficiency of the combined repairing techniques was evaluated taking into consideration the structural performance of the collar truss, namely its displacement and ultimate load capacity. In this paper, the results of the experimental tests are discussed attending to the analytical calculation of the contribution of the repairing techniques. Also, the different failure scenarios, for original and strengthened truss, were analyzed and compared.

\section{Introduction}

Historic timber trusses are part of the architectural heritage of the Mediterranean Region and represent one of the most important types of ancient structures [1]. To conserve their worth and the original material, structural repairs and reinforcements may be needed for different reasons such as change of use, deterioration, exceptional damaging events or loadings, later changes in regulatory specifications, or interventions to increase structural performance. Different structural types of timber trusses exist and the knowledge of the mechanical behaviour of these structures is needed to design appropriate strengthening and repair interventions. However, testing the overall behaviour of timber trusses is often not possible and few studies deal with such topic. Branco et al. [2] investigated the behaviour of two traditional king-post trusses on a
\end{abstract}


full-scale load-carrying test under symmetric and asymmetric loading, to identify suitable reinforcement strategies. Parisi and Piazza [3] tested a full-scale roof compound truss (king-post truss superimposed above queen-post truss) of Silver fir (Abies alba Mill.), of mid-XIX century, to validate a numerical model developed for the analysis of timber structures in seismic conditions. Barbari et al. [4] tested a full-size prototype of a traditional timber truss, to verify the mechanical behaviour of an original joint connection system between the top-chord and the tie beam.

In this work, a collar truss is analyzed based on the results of a full-scale load-carrying test. This type of roof structure was developed to provide more internal room height without increasing the overall height of the construction. The collar beam truss has a tie beam at the mid-height [5], with a different connection system to the inclined rafters from the tie beam of traditional king-post trusses [6-8]. The most common and dangerous damage for this type of truss structure, may occur at the joint connection of the rafters with the tie beam and at the rafters ends (e.g. by rot due to water infiltration). Also, due to its configuration, they are very susceptible to horizontal loading as in the case of seismic action, because they transmit a significant thrust to the supporting walls (often masonry walls). In these cases, repairing interventions are needed to avoid the collapse of the structure. Currently, the use of steel and fiber reinforced polymers (FRP), made of glass or carbon fibers, are the most common solutions for the reinforcement of timber elements in existing structures [9-13]. The choice of the appropriate strengthening and repairing method depends on the work situation and on the safety level required.

The aim of this study is to compare two different intervention techniques that can be used onsite, in a short time period, taking into consideration the structural performance of the truss during both load-carrying tests (before and after intervention).

\section{Materials and Methods}

The Collar Beam Truss. The timber truss analyzed was salvaged during the restoration of the Chimico Laboratory's roof in Coimbra, Portugal, built at the end of $18^{\text {th }}$ century. Four pine timber trusses with $14.2 \mathrm{~m}$ span, constituted the roof structure. Two of them had later additions and strengthening interventions. The collar beam trusses were constructed with an iron tie at the base and a timber tie beam at mid-height, Fig. 1 [5]. The iron tie prevented problems associated to horizontal thrust which could be increased in an earthquake. Due to large damage and degradation, the trusses were brought down and assessed and considered unsuitable for the new use of the building. Two of them, were dismantled and moved to the Laboratory of the Civil Engineering Department of University of Minho in Guimarães, and reassembled in order to perform mechanical tests and research studies. The present work considers the analysis of one of these collar beam trusses.

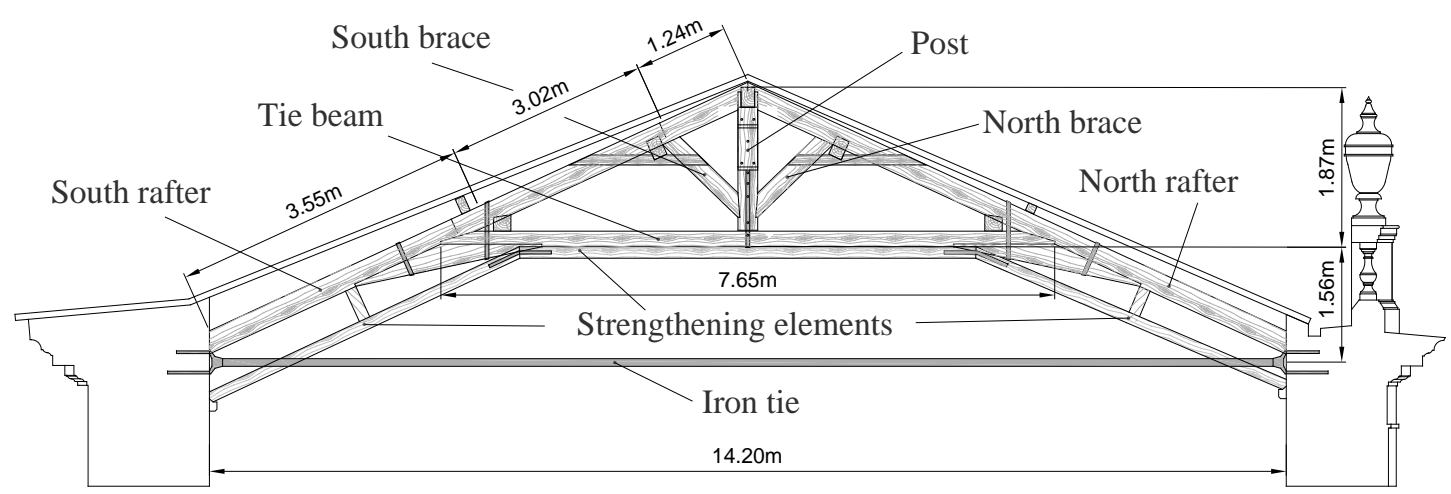

Fig. 1 - Roof structure of the Chimico Laboratory in Coimbra [5]. 
Load-carrying Tests. A full-scale load-carrying test was carried out by loading both rafters between the strut (south brace and north brace, Fig. 1) and the joint connection with the tie beam (Fig. 2). Linear variable displacement transducers (LVDT) were used to measure the displacements of the timber elements and to evaluate the entire behaviour of the truss under loading condition. The vertical load was applied with displacement control (displacement rate of $0.05 \mathrm{~mm} / \mathrm{s}$ ) by two hydraulic jacks fixed to the floor slab of the laboratory. A wood wedge was placed between the rafter and the loading heads, in order to have a better load distribution and to minimize local indentations. Steel frames were used to restrain out-of-plane movement of the truss. In addition, the horizontal movement of the rafters was restrained, aiming at replicating the on-site conditions (Fig. 1), where a metal tie rod was used to restrain horizontal movement, and to minimize the thrust transmitted to the masonry walls. Taking into account these boundary conditions, the test setup was made in order to simulate pinned support conditions. Load was applied until visible failure was obtained in both sides of the truss. Then, two repair interventions were made and the same testing procedure was performed.

Failure of the truss was found in both rafters near the loading position and on the connection between one rafter and the post (Fig. 2). The failure of the rafters coincided with sections where significant knots were found on the tensioned side of the element. Slight crushing of the supports (bottom of the rafters) was also found (due to decayed segments).

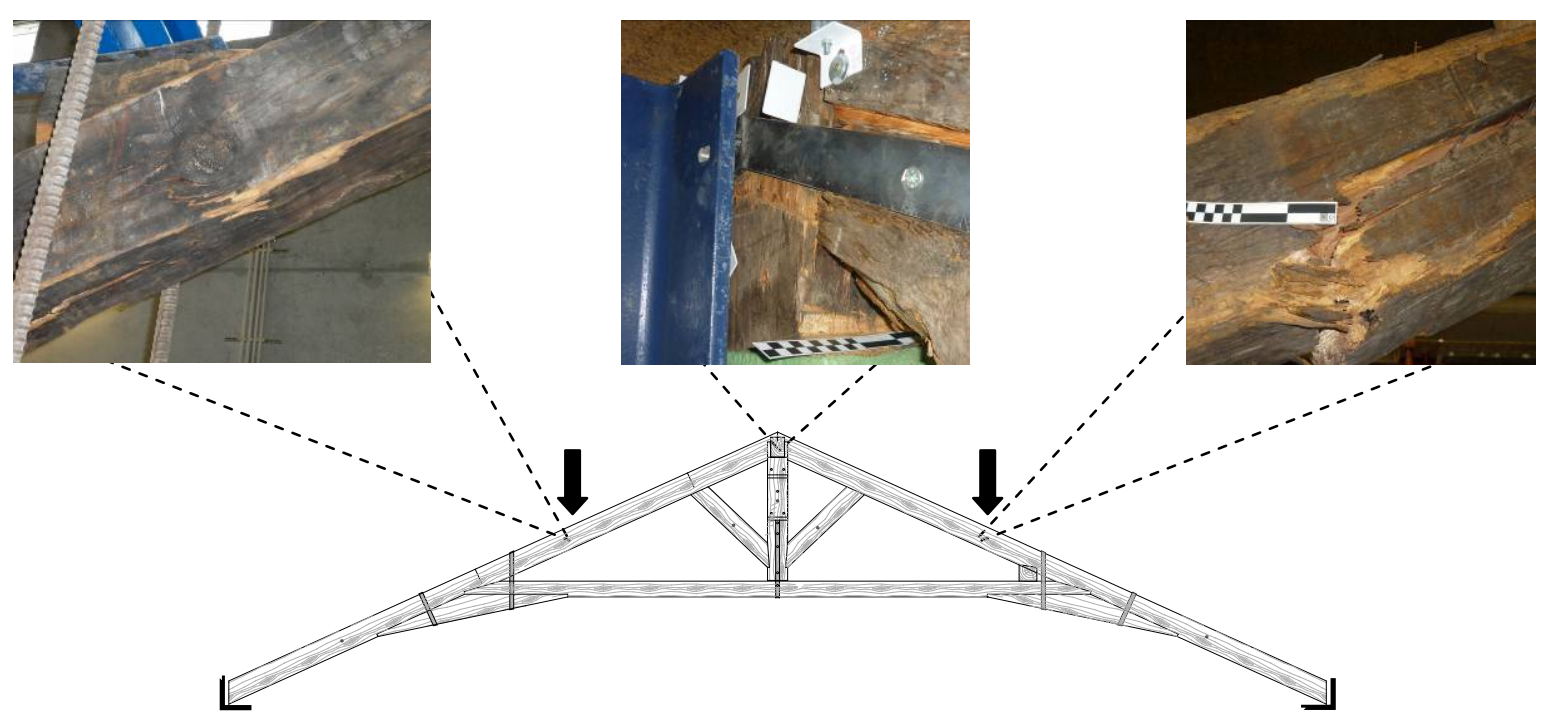

Fig. 2 - Schematic of test setup and details of the failure of the rafters and of the post-rafter connection.

Figure 3 presents the results of the load-displacement response of the truss on the loading points, where the first load decrease, found for each rafter, correspond to the initial failure (bending) on the rafters. Considering those results, a simple truss model was calibrated to determine the ultimate stress on each failed section. The cross-section dimensions were obtained through the geometrical survey of each element complemented with the information of non-destructive tests (namely pin penetration tests and drilling resistance tests) [14]. The connection between elements was simulated by hinges and the stiffness of each element was calibrated considering the displacement of the tiebeam and of the rafters at time of failure. The stresses found for each initial failure of the rafters are presented in Fig. 3b. It is noted that the stress conditions for the failure of the second rafter (rafter_2) took into account a decrease of approximately $10 \%$ of the cross-section height of the rafter that had the first failure (rafter 1 ). This reduction was obtained by the analysis of the local failures of rafter 1 and calculating the height that allowed maintenance of the same ultimate bending strength of that section during the test. 


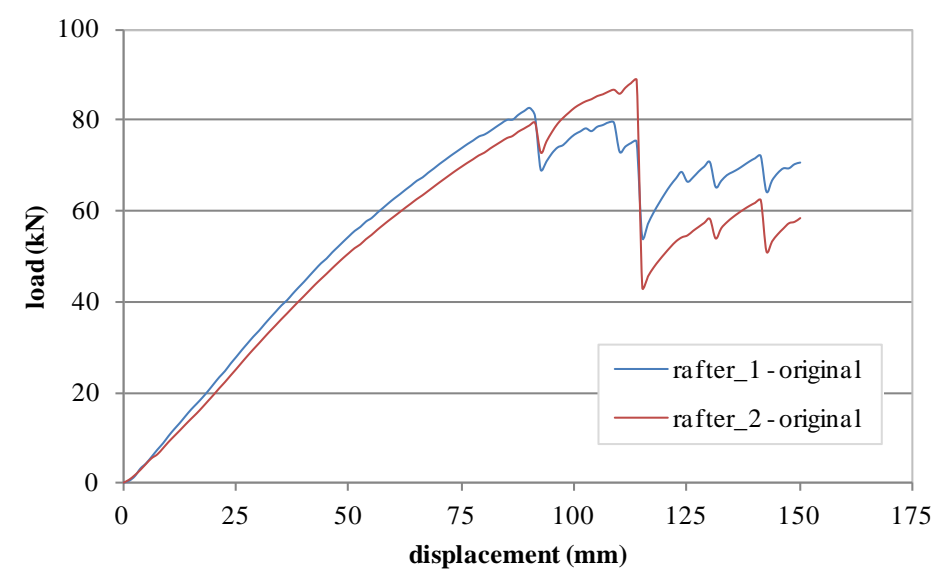

a)

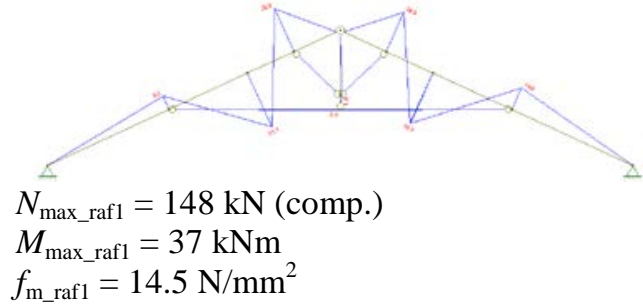

b)

Fig. 3 - Full scale test on the truss in original conditions: a) test results measured at the loading points on the rafters; b) simplified model and bending strength of the failed sections.

Repair Interventions. The initial step made within the repair interventions was to reestablish the state of deformation of the rafters prior to failure. To that aim, hydraulic jacks were used and a strut was placed between the tie-beam and the rafter while screws (VGZ $7 \times 340)$ were inserted in the rafters, in a $45^{\circ}$ angle with respect to the observed crack (Fig. 4b). The objective of these screws was only to close the crack and recover the initial configuration of the truss, and they should not be considered as influencing the strength of the element. After inserting the screws the strut was removed and the repair intervention was continued. Two different techniques were considered for the intervention on each side of the truss.

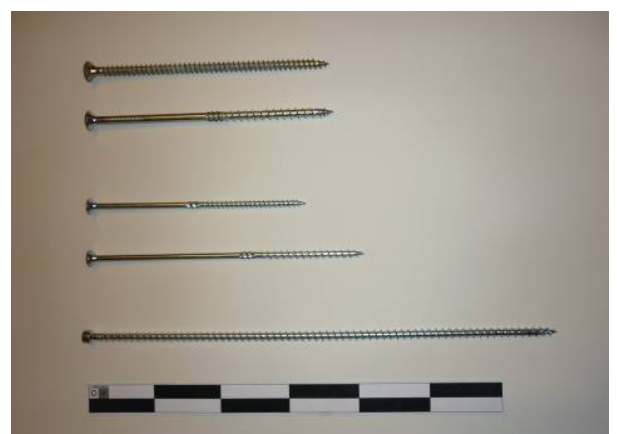

a)

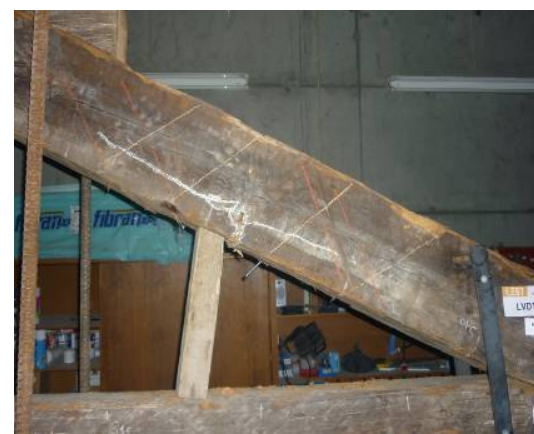

b)

Fig. 4 - a) Metallic screws used for the repair of the timber rafters; b) exemplification of the placing of a strut and of the inserting of inclined screws to close the existing cracks.

Repair with Timber Elements. In the first case, the cross-section was reinforced with timber elements placed on the sides of the cross-section by means of screws. On the edges of the new timber elements taken from remaining elements of the same original roof, screws (HBS 6×200) were inserted to connect the new timber element to the existing rafter, while perpendicular screws (HBS 6×160) were inserted along the segment where failure occurred (Figure 5). In this case, the contribution of the timber elements to the strength capacity of the cross-section mainly concerns the increase of its geometry (increase of width) using elements with the similar mechanical properties. For this type of repair, the contribution of the existing element should not be considered when determining the cross-section load bearing capacity. The inertia and area of the cross-section is only determined from the added timber elements. In this repair configuration (Fig. 5a), the area and inertia of the repaired cross-section is equal to the original as each element had half of the width of 
the original cross-section and the same height. Therefore, the bending strength of the repaired section is estimated to be similar to the original section, since the newly added elements were taken from a timber element with similar mechanical properties as the original rafter.

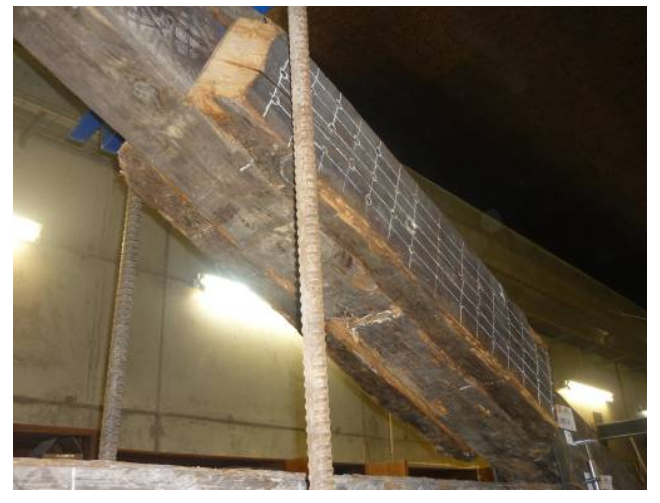

a)
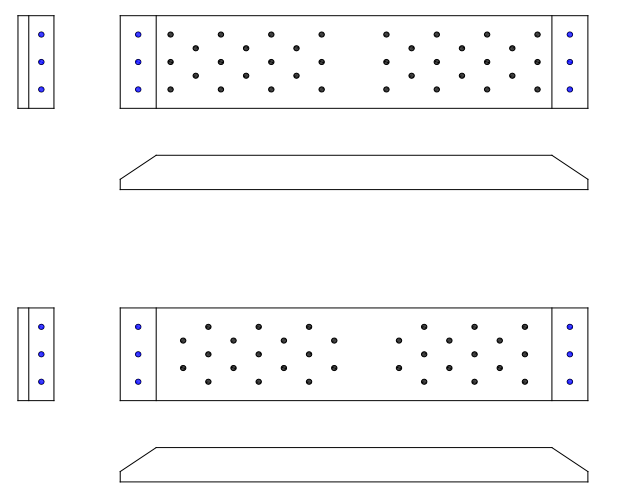

b) spacing:

$S_{\mathrm{x}}=14 \mathrm{~cm}$

$s_{\mathrm{y}}=4 \mathrm{~cm}$

Fig. 5 - Repair intervention on a rafter using timber elements: a) repair intervention onsite;

b) schematic of the location of the screw connectors.

The main function of the screws used in this system is to ensure that the stress field is uniformly distributed along the rafter element and the new added elements. Owing to the orientation of the screws regarding the load these are mainly under shear due to the axial stress present in the element. The calculation of the load bearing capacity of the screws are made taking into account that the group of screws located either before or after the failed section must be sufficient to carry the existing stress level.

As one of the objectives of this repair was to reestablish the load bearing capacity of the original truss minimizing the use of screws, the residual cross-section of the rafter was calculated by considering the residual load that was still sustained after the initial failure. This is only admissible due to the existence of data of the full-scale test. In this experimental campaign, a value for the residual area of $80 \%$ of the original area was obtained according to the simplified numerical model. Owing to the presence of knots located near the critical section, the residual cross-section was reduced to $65 \%$ of the original section. In onsite conditions, where the load level capacity after initial failure cannot be quantified, the residual cross-section should not be considered.

The maximum normal force observed during the first test was $166.3 \mathrm{kN}$. Considering the contribution of the residual cross-section, each side of the connection system should be able to sustain $58.2 \mathrm{kN}$. Attending to the configuration presented in Fig. 5b, the bearing capacity of the connections, calculated through Eurocode 5 [14] and also attending to the manufacturers the European Technical Approval [15], was equal to $F_{\mathrm{V}, \mathrm{Rk}}=58.4 \mathrm{kN}$, therefore being suitable for the this load level. Disposition of screws attended to [16] recommendations and to the manufacturers' guidelines, aiming at maximizing the performance of the effective number of screws.

Repair with Metal Plates. The second intervention technique considered the use of steel plates placed on the bottom face of the cross-section, which corresponded to the tension side where failure was initiated. Two types of screws were used for this connection namely screws HBS $8 \times 180$ and fully threaded screws $(8 \times 180)$. The screws were inserted perpendicular to the elements' bottom face fixing the metal plates to the timber element. Due to the configuration of the cracks, two metal plates (5 mm thickness) were used. In order to ensure a suitable safety level, the load carrying capacity of both connection systems was preliminarily calculated using the ultimate load, according to Eurocode 5 and ETA-11/0030 (2012) [15,16]. The distribution of bending stress found in the mechanically jointed section using the failure load level previously observed is presented in Fig. 7. 


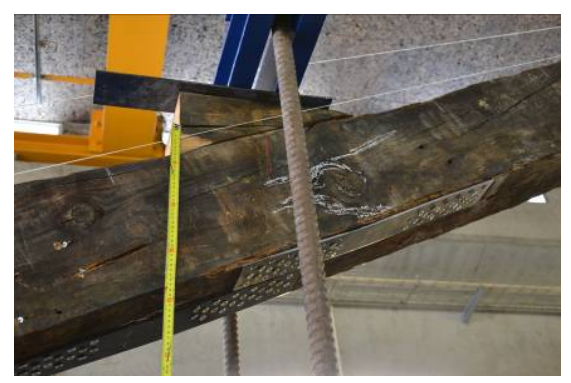

a)

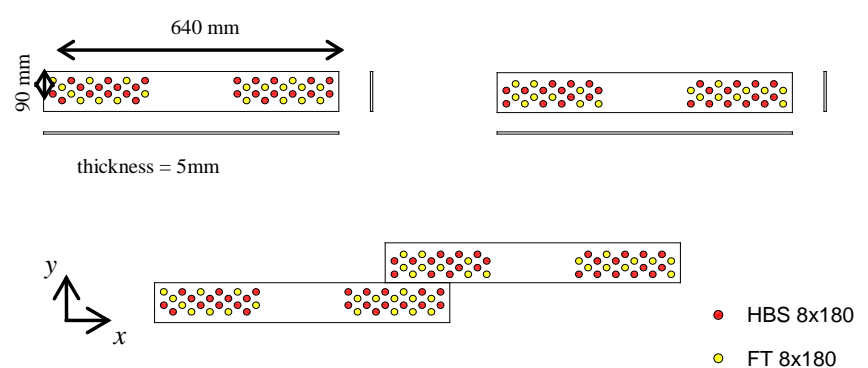

b)

Fig. 6 - Repair intervention on a rafter using steel plates: a) repair intervention onsite; b) schematic of the location of the screw connectors.
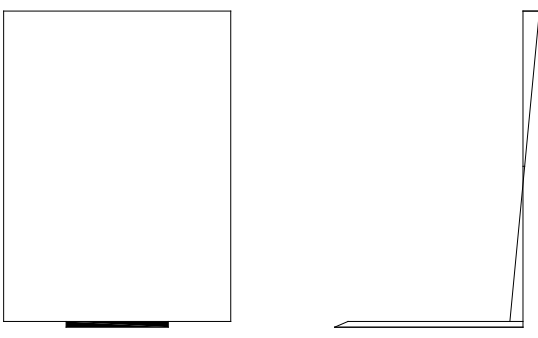

$$
\begin{gathered}
\sigma_{\text {wood,max }}^{-}=14.5 \mathrm{~N} / \mathrm{mm}^{2} \\
\sigma_{\text {wood,max }}^{+}=11.5 \mathrm{~N} / \mathrm{mm}^{2} \\
\sigma_{\text {steel,min }}^{+}=154.2 \mathrm{~N} / \mathrm{mm}^{2} \\
\sigma_{\text {steel,max }}^{+}=165.9 \mathrm{~N} / \mathrm{mm}^{2}
\end{gathered}
$$

Fig. 7 - Repair intervention on a rafter using timber elements: a) repair intervention onsite;

b) schematic of the location of the screw connectors.

According to Eurocode 5 [15], considering a repair solution using only normal screws (with lower characteristic shear strength compared to the chosen fully threaded screws) leads to a value of load per fastener of $4.15 \mathrm{kN}$. For the proposed repair configuration a $F_{\mathrm{V}, \mathrm{Rk}}=4.18 \mathrm{kN}$ is obtained for each effective screw (using only HBS $8 \times 180$ screws). Considering the stress level on the shear plane, a total of 18 screws would be necessary to efficiently fix each side of each steel plate. Disposition of screws attended to Eurocode 5 [15] recommendations and to the manufacturers' guidelines, aiming at maximizing the performance of the effective number of screws. Taking into account the use of fully threaded screws and the required number of effective screws a total of 22 screws were used for each side.

\section{Results and Discussion}

Efficiency of the repair techniques. Figure 8 shows the load-displacement graphs, before and after the repair interventions, measured at the loading points on the rafters. It is possible to note that the ultimate load achieved with the original truss was not reached with the repaired one. In fact, the maximum load (at failure) of the repaired rafters was, using both repair techniques, approximately $80 \%$ of that of the original rafters (Tab. 1). In addition, as expected, a different stiffness was observed due to loss of rigidity of the connections and also due to local failures along the elements. The screws used in both repair interventions presented no failures, but the stiffness of the metal plates was not sufficient to avoid local deformation of the timber element.

The repaired truss did not achieve the same load level of the original truss due to the fact that different failure conditions were found (further detailed in the following topic). However, if the truss had to be repaired onsite, the obtained results could be considered suitable for serviceability states. Moreover, in the past, timber elements were overdesigned (very large cross-sections), therefore, for this case, a cost effective repair solution could consider a lower level of load than the original ultimate load. 


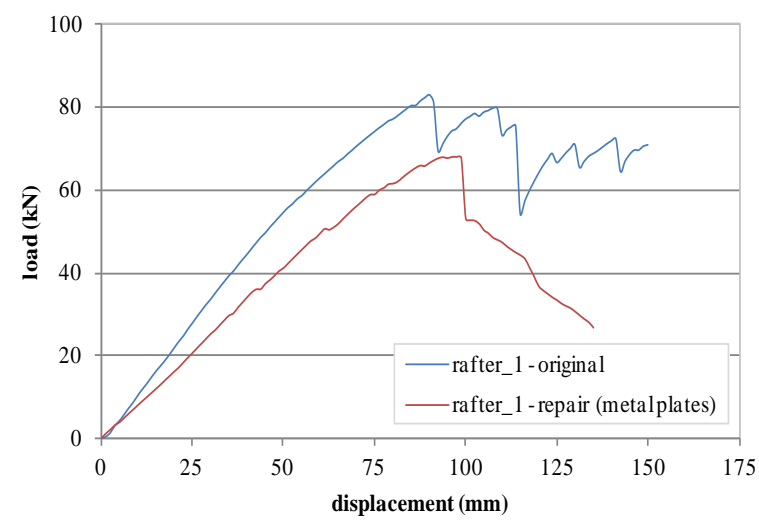

a)

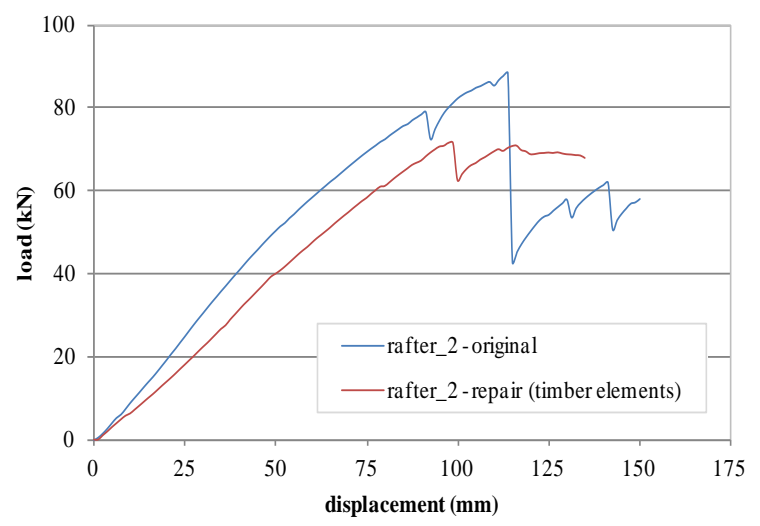

b)

Fig. 8 - Comparison between original and repaired truss with: a) metal plates; b) timber elements

Table 1 - Ultimate load results and efficiency of the repair techniques

\begin{tabular}{llccc}
\hline Description & Property & Unit & Rafter 1 (metal plates) & Rafter 2 (timber elements) \\
\hline \multirow{2}{*}{ Original } & load $_{1 \max }$ & {$[\mathrm{kN}]$} & 82.8 & 88.7 \\
& displacement $_{1}$ & {$[\mathrm{~mm}]$} & 90.1 & 114 \\
\hline \multirow{2}{*}{ Repaired } & $\operatorname{load}_{2 \max }$ & {$[\mathrm{kN}]$} & 68.1 & 71.4 \\
& displacement $_{2}$ & {$[\mathrm{~mm}]$} & 97.4 & 97.4 \\
\hline \multirow{2}{*}{ Efficiency } & $\operatorname{load}_{2 \max } / \operatorname{load}_{1 \max }$ & {$[\%]$} & 82.2 & 80.6 \\
& displacement $_{\text {load2max }}$ & {$[\%]$} & 144 & 126 \\
\hline
\end{tabular}

${ }^{a}$ ratio between the displacements of original and repaired rafters for the $\operatorname{load}_{2 \max }$ value (i.e. value of displacement of the original truss corresponding to a load equal to $\operatorname{load}_{2 \max }$ )

Comparison between the two repair methods. Different failure scenarios occurred between the two rafters and, therefore, between the two repair methods. Figure 9 depicts the load-displacement graph. The first drop of the load corresponded to failure of the rafter 1 (around $72 \mathrm{kN}$ ), where the metal plates were placed. For the repaired side with timber elements, the load after the first drop slightly rises and then maintains the same value (around $70 \mathrm{kN}$ ) until the end of the test; while for the rafter 1 the displacement increases without any upturn of the load. This behaviour was due to the fact that other failures occurred in different places of the truss destabilizing the structure and not allowing the same load distribution as seen in the original truss.

a)

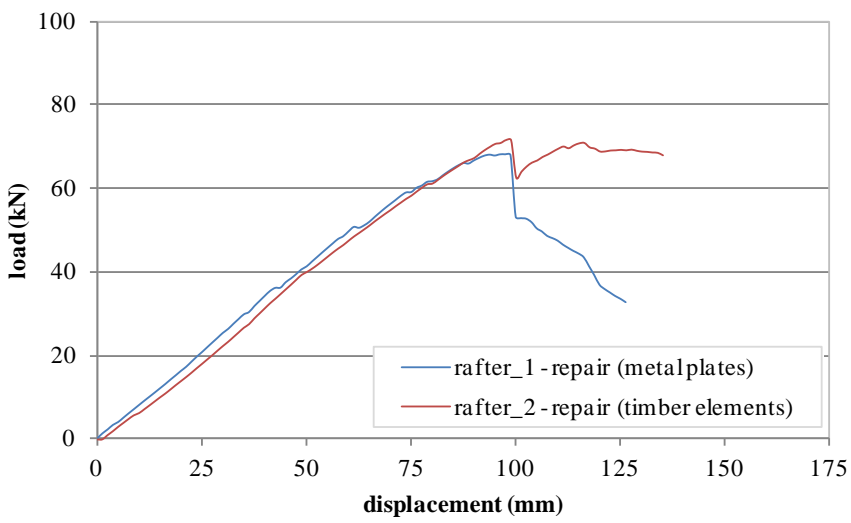

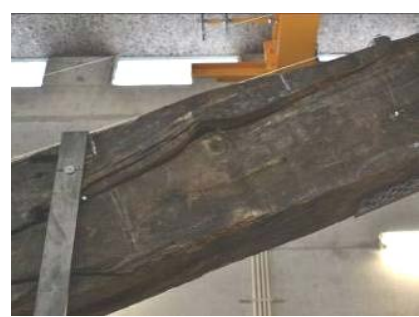

b)

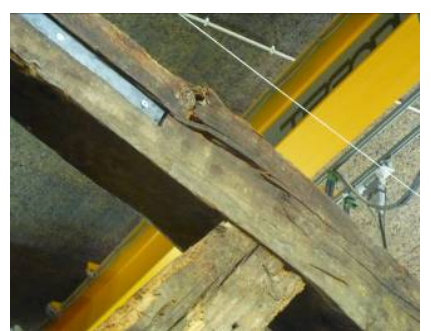

Fig. 9 - Rafters in repaired conditions: a) test results; b) failures on the top side of rafter 1 
Once the repaired timber cross-section strength of rafter 1 was exceeded, the metal plates prevented the collapse of the truss shifting the stress distribution to other points of the structure. As a result, additional failures took place in rafter 1, namely on the top surface of the previous failed section (near the connection with the tie-beam), and after the strut (Fig. 9.b). Moreover, the truss started to have a significant out-of-plane behaviour, as the rafters began to incline around their axis, especially rafter 1 . Therefore, the use of metal plates was not able to reestablish the same load bearing capacity of the original truss (due to its low stiffness). On the other side, the added timber elements allowed a better performance and are recommended in case of fire as they are less sensible than exposed metal plates. However, it was not possible to fully determine the efficiency of the connection system in the repaired sections because failures were observed in other sections.

\section{Conclusions}

An old collar timber truss was taken to failure in a full-scale load carrying test and the ultimate load and strength were recorded. In order to repair and reestablish the load bearing capacity of the original truss, two techniques were made with the use of screwed timber elements and screwed metal plates. Both tested repair techniques showed equivalent efficiency (around 80\%) in terms of load-carrying capacity. However, this result was influenced by other sections (not repaired), that were damaged in the first test. Also the utilized metal plates were not sufficiently rigid to avoid the increase in displacement and out-of-plane behaviour. Although the achieved level of load with both techniques was suitable for serviceability states, the use of timber elements was more compatible with wood and with the structural performance of the tested collar truss. When choosing which technique to use, ease of attachment and aesthetics need to be considered. Using timber elements is uniform with the materials of the old structure. Metal plates are fast to attach to the area needing reinforcement but the use of metal plates may interfere with the aesthetics of historic buildings and also the fire resistance. Finally, a careful assessment of the failure and of the effective residual timber section is important for choosing the most appropriate repair technique.

\section{Acknowledgments}

The first and second authors would like to express their gratitude for the grant provided by training school: Assessment and reinforcement of timber elements and structures (Guimarães, Portugal) within the scope of FP1101 and RILEM TC 245. The present work was made within a homework task regarding that training school. The authors acknowledge the support of the Structural Lab from University of Minho (test facilities). The assistance of Eng. Ricardo Braz from Rotho Blaas in the definition of the repair solutions and material provided are acknowledged. The authors acknowledge also the support and assistance of Augusto de Oliveira Ferreira e Companhia Lda (AOF).

\section{References}

[1] Tampone G., 2001, Acquaintance of the ancient timber structures. In: 3rd International Seminar of Historical Constructions, Guimarães, Portugal, pp. 117-144.

[2] Branco J.M., Piazza M., Cruz P.J.S., 2010, Structural analysis of two King-post timber trusses: Non-destructive evaluation and load-carrying tests. Construction and Building Materials, 24, pp. 371-383. doi: 10.1016/j.conbuildmat.2009.08.025.

[3] Parisi M.A., Piazza M., 2002, Seismic behavior and retrofitting of joints in traditional timber roof structures. Soil Dynamics and Earthquake Engineering, 22, pp. 1183-1191. doi: 10.1016/S0267-7261(02)00146-X.

[4] Barbari M., Cavalli A., Fiorineschi L., Monti M., Togni M., 2014, Innovative connection in wooden trusses. Construction and Building Materials, 66, pp. 654-663. doi: 10.1016/j.conbuildmat.2014.06.022. 
[5] Lourenço P.B., Sousa H.S., Brites R.D., Neves L.C., 2013, In situ measured cross section geometry of old timber structures and its influence on structural safety. Material and Structures, 46, pp. 1193-1208. doi: 10.1617/s11527-012-9964-5.

[6] Branco, J., Cruz, P., Piazza, M., Varum, H., 2006, Behaviour of traditional Portuguese timber roof structures. In: Proceedings of World Conference on Timber Engineering, Portland.

[7] Levandoski J., 2006, Kingpost trusses, in “Historic American roof trusses”, edited by Kenneth Rower, Becket, Massachusetts: Timber Framers Guild.

[8] Sobra K., Branco J.M., Aranha C.A., 2014, Application of the component method to traditional dovetail joints of timber trusses. Materiais de Construção Sustentáveis, 2, pp. 187-197.

[9] Akbiyik A., Lamanna A.J., Hale W.M., 2007, Feasibility investigation of the shear repair of timber stringers with horizontal splits. Construction and Building Materials, 21, pp. 991-1000. doi: 10.1016/j.conbuildmat.2006.03.004.

[10] Schober K.U., Rautenstrauch K., 2007, Post-strengthening of timber structures with CFRP's. Material and Structures, 40, pp. 27-35. doi: 10.1617/s11527-006-9128-6.

[11] Richter K., Cruz H., 2008, Bonding of Timber. COST Action E34 - Working group 1: Bonding on site. Core document. 7-98.

[12] Borri A., Corradi M., 2011, Strengthening of timber beams with high strength steel cords. Composites Part B: Engineering, 42, pp. 1480-1491. doi: 10.1016/j.compositesb.2011.04.051.

[13] Nowak T.P., Jasieńko J., Czepiżak D., 2013, Experimental tests and numerical analysis of historic bent timber elements reinforced with CFRP strips. Construction and Building Materials, 40, pp. 197-206. doi: 10.1016/j.conbuildmat.2012.09.106.

[14] Gomes I.D., Kondis F., Sousa H.S., Branco J.M., Lourenço P.B., 2015, Assessment and diagnosis of two collar timber trusses by means of visual grading and non-destructive tests. HEaRT2015, Lisbon, Portugal.

[15] CEN (2004) EN 1995-1-1:2009 - Eurocode 5 - design of timber structures - Part 1-1: general - common rules and rules for buildings. National specifications, national comments and national supplements concerning ÖNORM EN 1995-1-1. European Committee for Standardization (CEN), Brussels (EN 1995-1-1:2009).

[16] ETA-11/0030 (2012) European Technical Approval issued by ETA-Danmark A/S for Selftapping screws for use in timber structures approval issued first 11/08/2012; approval holder: Rotho Blaas s.r.l, Italy. 